\title{
A Climatology of Southern Appalachian Cold-Air Damming*
}

\author{
JARED A. RACKLEY AND JOHN A. KNOX \\ Department of Geography, The University of Georgia, Athens, Georgia
}

(Manuscript received 7 April 2015, in final form 18 December 2015)

\begin{abstract}
A 30-yr climatology (1981-2010) of cold-air damming (CAD) events in the southern Appalachians was conducted using hourly surface observations and North American Regional Reanalysis (NARR) data. Analysis of the spatial distribution and frequency of these events reveals that some part of the Southeast is affected by CAD on 50 days out of each year, and even the northern Florida panhandle and much of Alabama experience CAD conditions on about 30 days annually. Spatially, different CAD types tend to exhibit one of two patterns in the southernmost extent of the cold-air dome: a more southerly dome with a ridge axis oriented from north-northeast to south-southwest or a more westerly dome with a ridge axis in a northeast to west-southwest orientation. These patterns may be the result of both splitting around the region of higher terrain in east-central Alabama and Coriolis forcing in stronger CAD types with higher wind speeds. Analysis of the frequency of CAD by type on a month-by-month and year-by-year basis confirms previous work that $\mathrm{CAD}$ is much more frequent during the cold season versus the warm season, with CAD occurring on 6.8 days month ${ }^{-1}$ during December and only 1.3 days $^{\text {month }}{ }^{-1}$ during July. Analysis was also stratified by CAD type, revealing that weak/dry events were the most common. Classical type events with stronger and more favorably positioned parent highs exhibited the longest average duration, nearly $45 \mathrm{~h}$, while other CAD types averaged approximately half as long.
\end{abstract}

\section{Introduction}

Topography is known to affect synoptic and mesoscale weather patterns throughout the world. One such effect, cold-air damming (CAD), occurs when a shallow, surfacebased layer of relatively cold air becomes entrenched against the windward side of a mountain range (Richwien 1980). The shallow dome of cold and stable air that becomes established during a CAD event is often identified by the characteristic "U"- or "wedge"- shaped inverted ridge that appears in the sea level pressure field and is typically only present below the $850-\mathrm{hPa}$ pressure level (Baker 1970; Bell and Bosart 1988; Lackmann 2011, 306309). CAD can also be observed in the near-surface temperature field, where the difference in temperature

\footnotetext{
* Supplemental information related to this paper is available at the Journals Online website: http://dx.doi.org/10.1175/WAF-D-150049.S1.

Corresponding author address: John A. Knox, Dept. of Geography, Rm. 204, The University of Georgia, 210 Field St., Athens, GA 30602.

E-mail: johnknox@uga.edu
}

between the damming region and coast can exceed $20^{\circ} \mathrm{C}$ during strong CAD events (Bell and Bosart 1988).

Cold-air damming can best be described as the effects of "orographically modified geostrophic balance" (Bell and Bosart 1988) when statically stable flow encounters a mountain barrier. In the southeastern United States, CAD generally occurs when a strong surface anticyclonic system (typically 1030-hPa central pressure or higher), referred to as the "parent high" (Bailey et al. 2003), is situated to the north of the Appalachians (most favorably north of $40^{\circ} \mathrm{N}$ ). As air parcels within the geostrophic flow about the parent high approach the Appalachians from the east, the parcels' westward momentum is decreased and convergence occurs near the Appalachian barrier (Smith 1982). This weakens the northward-directed component of the Coriolis force and the flow turns to the south and accelerates in response to the now-unbalanced pressure gradient force. As the ageostrophic northerly flow accelerates, the Coriolis force strengthens once again and acts to deflect the flow in a toward-barrier direction, causing both an accumulation of mass and orographic ascent along the eastern Appalachian slopes. The mass accumulation and adiabatic cooling due to the orographic 
ascent cause a hydrostatic pressure increase. Geostrophic adjustment occurs when the resulting pressure gradient force acting in the away-from-barrier direction is kept in near balance by the toward-barrier Coriolis force, creating and maintaining a strong northerly flow (Baker 1970; Richwien 1980; Bell and Bosart 1988; Xu 1990; Xu and Gao 1995). The cold advection favored in this flow results in increased static stability and enhanced hydrostatic pressure rises (Xu et al. 1996). Diabatic processes (i.e., clouds and precipitation) can also play an important, though usually secondary, role in cold-air dome maintenance through evaporational cooling and solar sheltering (Forbes et al. 1987; Bell and Bosart 1988; Lee et al. 1992; Fritsch et al. 1992; Langmaid and Riordan 1998; Bailey et al. 2003). As the cold airflow nears the southern extent of the damming region, the pressure gradient and Coriolis forcings are weakened and the flow begins to spread outward.

Though forecast accuracy and knowledge of CAD events have improved substantially over the past four decades, CAD remains a well-known challenge to operational forecasters in the southeastern United States (Baker 1970; Bell and Bosart 1988; Hartfield 1998). While not all CAD events are strong, many have a significant impact on the region's sensible weather, including temperature, sky cover, and precipitation. In particular, CAD is known to affect precipitation type during the cold season (e.g., Forbes et al. 1987; Keeter et al. 1995) and trigger convection along the cold-dome periphery, or "wedge front," during the warm season (Bosart et al. 1972; Ballentine 1980; Garreaud and Wallace 1998; Baker 2009). While modern mesoscale numerical models have significantly improved the forecasting capabilities of CAD events in the past two decades, the models still have a tendency to underestimate CAD impacts and duration, often eroding the cold-air domes prematurely (Forbes et al. 1987; Stauffer and Warner 1987; Bell and Bosart 1988; Keeter et al. 1995; Kramer 1997; Stanton 2003; Lackmann and Stanton 2004; Green 2006). Even today's rapidly updating, high-resolution mesoscale models (e.g., the High-Resolution Rapid Refresh) show a tendency to underestimate the effects of solar sheltering and erode the cold-air dome too quickly (Grumm 2015).

Bell and Bosart (1988) conducted a relatively long climatology of CAD events using a nonobjective classification scheme, and Bailey et al. (2003) conducted a shorter 12-yr climatology using objective and expanded classifications. However, a long-term climatology using the objective scheme has not been performed. Furthermore, while surface conditions (e.g., cloud cover, temperature, and sea level pressure) have been observed to be relatively homogeneous within the cold dome, the previous literature largely ignores the varying degree of effects that CAD can have on conditions along its southernmost extent, namely central Georgia and even sometimes eastern Alabama. While cold domes have been observed to penetrate as far to the southwest as Birmingham, Alabama, weaker cold-air domes may only extend into northeastern Georgia. The extent to which CAD protrudes to the southwest can have significant impacts in this region. This study seeks to investigate these largely ignored varying impacts along the southernmost extent of CAD.

The primary objectives of this study are to 1) update the previous CAD literature with an extended objective climatology, 2) determine the previously unstudied frequency and spatial pattern of CAD impacts in the southern extent of the damming region, and 3) determine station-to-station $\mathrm{CAD}$ frequency variations from the CAD climatology as a whole.

\section{Data and methodology}

\section{a. CAD detection algorithm}

An updated and extended objective climatology of CAD was constructed using the Bailey et al. (2003, hereafter B03) objective CAD-identification algorithm. To identify a full spectrum of CAD events objectively, the CAD-detection algorithm was adapted and run for the 30-yr period from 1981 to 2010. This algorithm was designed to identify the characteristic inverted pressure ridge, cold-air dome, and ageostrophic northeasterly flow associated with CAD events using hourly surface observations and Laplacians $\nabla^{2} x$ of sea level pressure $P_{\mathrm{SLP}}$ and potential temperature $\theta$ in the mountainnormal direction. Following B03, Laplacians were evaluated using Python scripting for three mountainnormal lines of surface observations and a single mountain-parallel line that represents the northeasterly flow (Fig. 1). Each line contains surface observations from three stations within the damming region, with the center station representing the core of the damming region, and the stations on either side approximately perpendicular to the Appalachian Mountains. Line A consists of the following stations: Charleston, West Virginia (CRW); Lynchburg, Virginia (LYH); and Norfolk, Virginia (ORF). Line B includes: Bristol, Tennessee (TRI); Greensboro, North Carolina (GSO); and Wilmington, North Carolina (ILM). Knoxville, Tennessee (TYS); Greenville-Spartanburg, South Carolina (GSP); and Charleston, South Carolina (CHS), make up line C. Laplacians are calculated along these lines using 


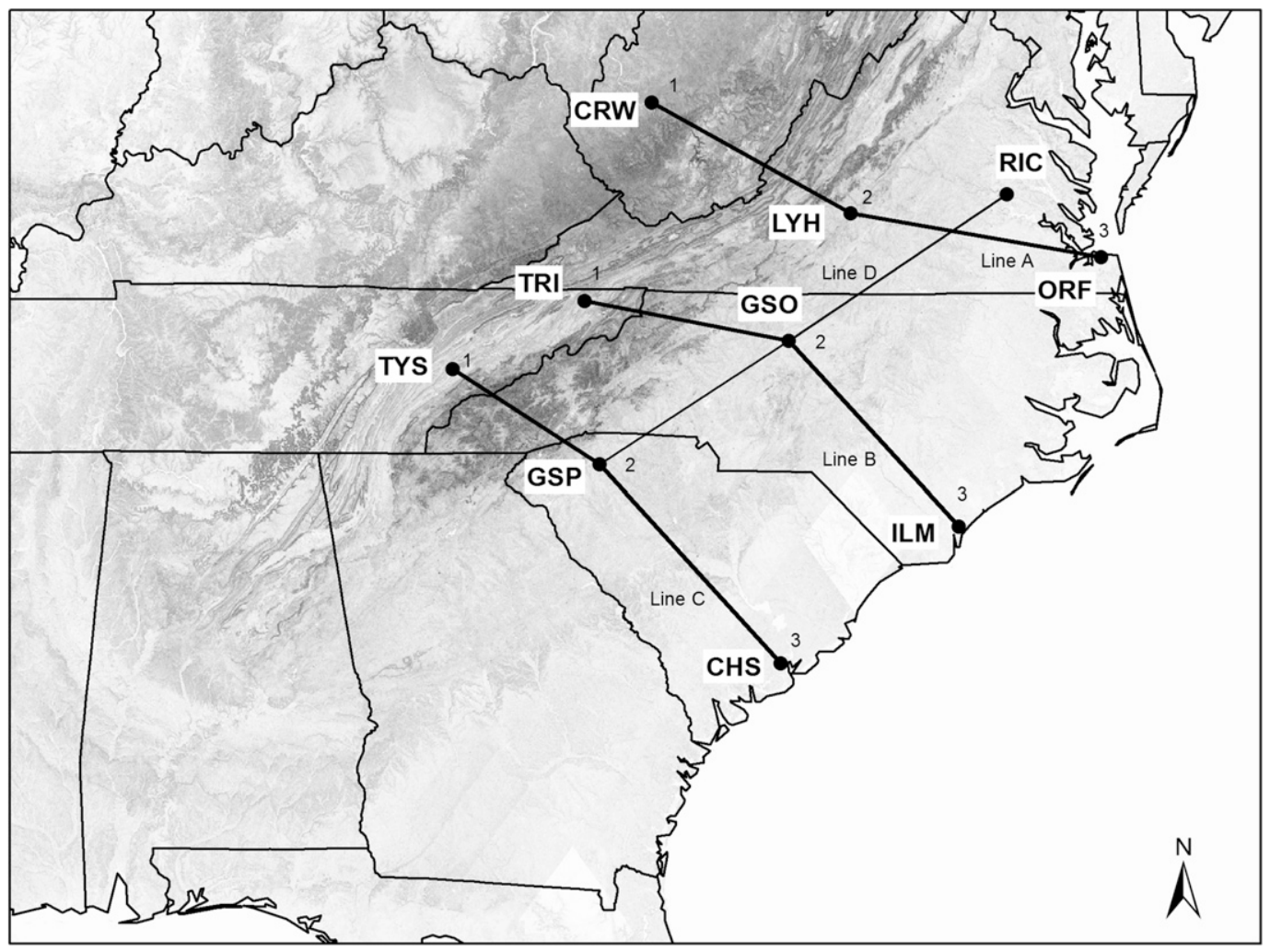

FIG. 1. The 10 surface stations and Laplacian lines constructed for the CAD detection algorithm (modified from Bailey et al. 2003).

$$
\nabla^{2} x=\frac{\frac{x_{3}-x_{2}}{d_{2-3}}-\frac{x_{2}-x_{1}}{d_{1-2}}}{\frac{1}{2}\left(d_{2-3}+d_{1-2}\right)},
$$

where $x$ is either the sea level pressure or the potential temperature and subscripts are stations from west to east along the mountain-normal line. In (1), $d$ represents the distance between stations. Negative values of $\nabla^{2} P_{\text {SLP }}$ are associated with a higher pressure at the center station, while positive values of $\nabla^{2} \theta$ are associated with colder potential temperatures at the center station.

Temporal and numerical thresholds for CAD detection were applied to computed values. These CAD detection criteria are summarized as follows:

- The mountain-normal Laplacian of sea level pressure must be negative and exceed in magnitude one standard deviation of the average of all the negative mountain-normal Laplacian values in the dataset.

- The mountain-normal Laplacian for potential temperature must be greater than zero.

- Sea level pressure must be greater at the center station relative to the end stations.

- The difference in the pressure along line $\mathrm{D}$ must be greater than $1.5 \mathrm{mb}(1 \mathrm{mb}=1 \mathrm{hPa})$ between either
GSP and GSO or GSO and RIC, with higher values to the northeast.

- All requirements must be met for at least six consecutive hours on at least one of the mountain-normal lines (A-C).

As with previous CAD climatologies, vertical atmospheric soundings were not used, despite their usefulness in identifying CAD presence and strength, because of their limited spatial and temporal resolution. Utilization of the B03 algorithm allows for objective detection, classification, and comparison with respect to previous studies.

While this study does not stray from the original B03 algorithm implementation, the data sources used for hourly observations used in this work differ from those used in B03. Hourly surface station observations were retrieved from the National Centers for Environmental Information (NCEI) Climate Data Online (CDO) database, while the previous study utilized the older Solar and Meteorological Surface Observation Network (SAMSON) archives. This study also chooses to linearly interpolate missing data for gaps of up to $6 \mathrm{~h}$ versus the 3-h limit used in B03, as this helped to eliminate falsely detected CAD demise due to brief data gaps.

To maintain consistency with previous studies and to check the algorithm's accuracy, identified events were compared to a subjectively identified list of $30 \mathrm{CAD}$ events 


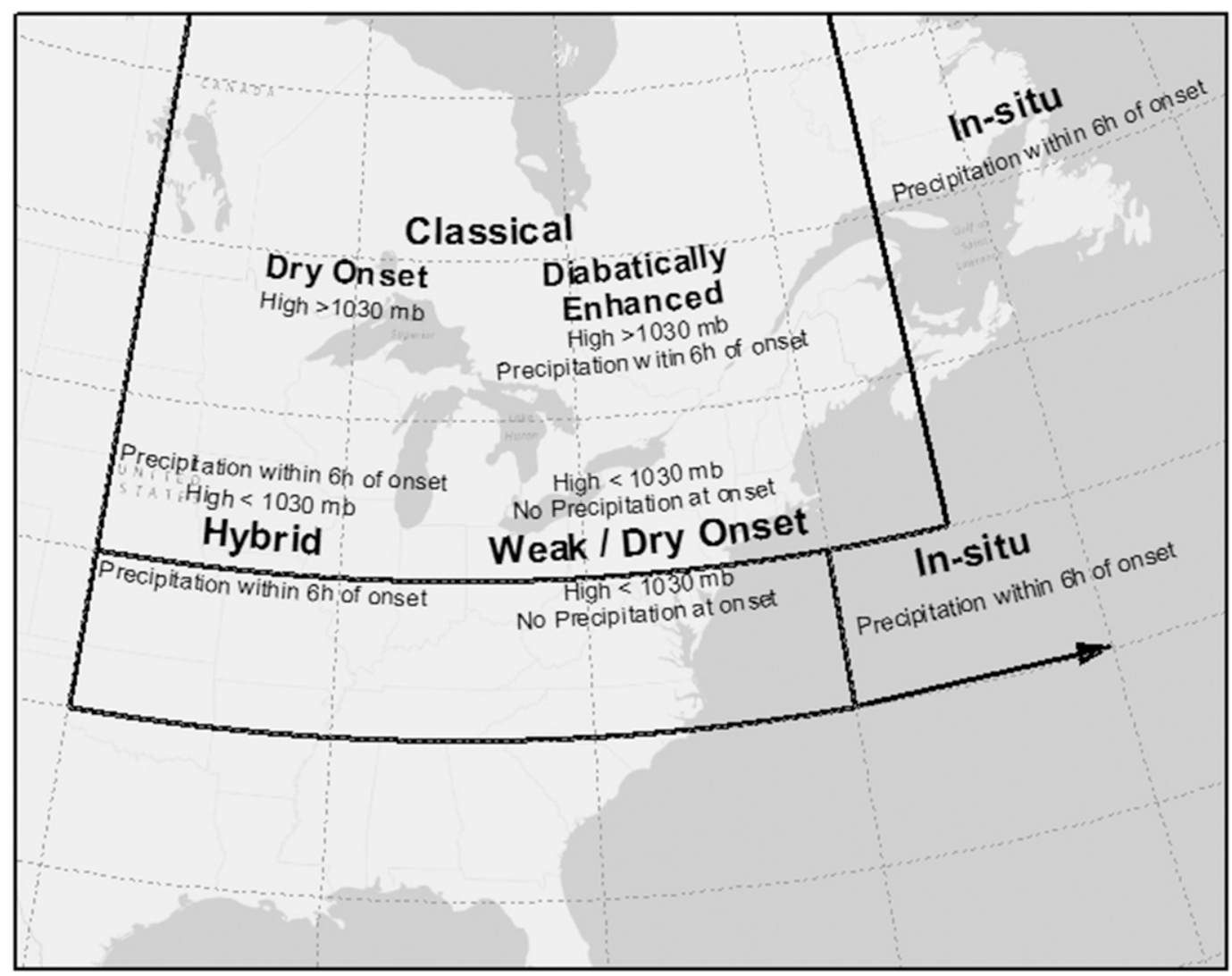

FIG. 2. Geographical domains applied to the location and intensity of the parent high at CAD onset for use in the CAD classification scheme (modified from Bailey et al. 2003).

from 1 January 2001 through 31 May 2002. This list was also used by B03, in which 26 of the 30 events were correctly identified. This study, using the criteria above, correctly identified all 30 events during the period. Surface analyses within the first several hours of initiation were viewed for each detected event, and no inconsistences were observed. Still, it should be noted that the algorithm missed several events when compared to subjectively identified CAD databases (e.g., Baker 2009).

In an effort to avoid overcounting a single CAD event that exhibits periods of weakening below algorithm thresholds, consecutive CAD events that are synoptically driven by the same parent high and separated by fewer than $18 \mathrm{~h}$ were analyzed using reanalysis and surface data and combined into a single event as necessary. While this deviates from previous uses of the CAD detection algorithm, we believe that this serves as a more realistic representation of each CAD event.

\section{b. Objective CAD classification scheme}

Detected CAD events were stratified into cases using the classification scheme outlined in B03. We summarize this scheme below for the reader.
The B03 classification scheme is a modification of the method developed by operational NWS forecasters (Hartfield et al. 1996; Kramer 1997; Hartfield 1998). Classification of each event was based on the strength and location of the parent high and whether or not precipitation was falling within $6 \mathrm{~h}$ of onset at the center station of the first line activated (Fig. 2). These criteria were determined using a combination of surface observations and North American Regional Reanalysis (NARR) data (Mesinger et al. 2006), and defined six CAD cases as discussed in B03:

1) Classical diabatically enhanced onset (CDEN)-At CAD onset, the parent high in the NCEP sea level pressure analysis must be centered north of $40^{\circ} \mathrm{N}$ between $100^{\circ}$ and $65^{\circ} \mathrm{W}$ with a central pressure greater than or equal to $1030 \mathrm{mb}$. This ensures that the anticyclone is strong and favorably positioned. Precipitation must be reported at the central stations in lines $\mathrm{A}, \mathrm{B}$, or $\mathrm{C}$ within $6 \mathrm{~h}$ of onset, and the total event duration must exceed $24 \mathrm{~h}$.

2) Classical dry onset (CDRY) - The same criteria as for CDEN except that no precipitation is reported within $6 \mathrm{~h}$ of onset and diabatic processes play a negligible role. 
3) Hybrid onset (HYBR) - Precipitation is reported at one or more of the center stations within $6 \mathrm{~h}$ of onset. The parent high must exhibit a central pressure of less than $1030 \mathrm{mb}$ and be centered between $100^{\circ}$ and $65^{\circ} \mathrm{W}$ if north of $40^{\circ} \mathrm{N}$ at onset or between $100^{\circ}$ and $70^{\circ} \mathrm{W}$, and the central pressure is not considered if the high is south of $40^{\circ} \mathrm{N}$. This ensures that the parent high is either weak or is not optimally positioned for $\mathrm{CAD}$, and that diabatic processes are capable of contributing to onset.

4) Weak/dry onset (WKDR)-The central sea level pressure in the parent high is less than $1030 \mathrm{mb}$, with the high centered between $100^{\circ}$ and $65^{\circ} \mathrm{W}$ and north of $40^{\circ} \mathrm{N}$, or south of $40^{\circ} \mathrm{N}$ and between $100^{\circ}$ and $70^{\circ} \mathrm{W}$ at onset. No precipitation is reported within $6 \mathrm{~h}$ of onset. This is consistent with weak synoptic forcing and a lack of a diabatic contribution.

5) In situ (INST) - Precipitation must be reported within $6 \mathrm{~h}$ of onset. If the parent high is south of $40^{\circ} \mathrm{N}$, then the parent high must be centered east of $70^{\circ} \mathrm{W}$. If the parent high is north of $40^{\circ} \mathrm{N}$, then the parent high must be east of $65^{\circ} \mathrm{W}$. These criteria represent cases where the high is unable to provide significant synoptic support to damming but had passed the region previously, leaving in place dry air at low levels.

6) Unclassifiable (UNKN) - All cases that do not fit one of the above categories.

\section{c. Cold-dome spatial extent}

To quantify the previously unstudied variation in spatial extent and frequency of cold-dome intrusion into the southeastern United States (i.e., South Carolina, Georgia, Alabama, and Florida), a climatology of cold-dome spatial extent was also conducted for the 30 -yr period. An objective CAD spatial extent algorithm was developed to identify the location of cold-air advection within the dome. While the previously discussed B03 algorithm generally determines whether CAD is present or not within the core damming region (i.e., Virginia, North Carolina, and South Carolina), this algorithm attempts to determine whether CAD is present at specified stations across the southernmost damming region. For simplicity, the algorithm relies on the assumption that northeasterly flow must be present and continuous from northeast to southwest within the cold-air dome of a damming event. Hourly wind observations of speed and direction for 21 stations across South Carolina, Georgia, Alabama, and Florida (see Table 1) were utilized to identify this. Selected stations were required to have a complete record for the period 1981-2010, and effort was made to maintain an adequate spatial distribution across the study area with stations located both within and without the assumed damming region.
Compiled times of CAD events identified by the detection algorithm were used to initialize the algorithm in order to reject cases of northeasterly cold-air advection unassociated with damming events. In short, no CAD events are diagnosed for the southernmost damming region without CAD also being present in the core damming region as per the B03 algorithm. Threshold values for acceptable wind directions at each station were selected based on an examination of wind observations during several CAD cases. The algorithm uses an upstream-todownstream hierarchical network, requiring that upstream (i.e., to the northeast) stations have flow within the specified threshold before downstream stations are checked for CAD. Upstream stations with missing data or calm conditions are considered to be within the dome if stations immediately downstream have flow within their specified thresholds. Upstream stations were also required to have greater or equal sea level pressure than their downstream counterparts. To reduce the error in the algorithm caused by variable wind direction that occasionally occurs within the dome, times were analyzed in rolling 3-h segments, requiring that conditions for the station must fall within the specified threshold during at least 1 of the $3 \mathrm{~h}$.

Calculated frequency of CAD by station was mapped both in total and stratified by CAD type and season using a GIS. The spline interpolation method (Burden and Faires 1993) was chosen to map the frequency of the CAD dome spatial extent using a smooth surface true to the sampled data points. For consistent comparison among CAD classes, map data were normalized by the total hours of CAD detected for each classification.

\section{d. Data}

Hourly surface observations for each station were obtained from the NCEI Global Surface Hourly database (DS3505) and were utilized in both CAD detection and CAD spatial mapping. Data for the 10 surface stations used in the CAD detection algorithm were downloaded for the full 30-yr period from 1981 to 2010. Meteorological fields included temperature, station pressure, sea level pressure, altimeter reading, and hourly precipitation. It was found that large portions of station pressure observations were missing for various stations within the archive even while sea level pressure observations and altimeter readings remained largely intact. Therefore, for times during which altimeter readings were recorded while station pressure was absent, the altimeter readings were used to compute the station pressure using

$$
P_{\text {stn }}=P_{a} \times\left[\frac{\left(R_{d}-0.0065 h_{m}\right)}{R_{d}}\right]^{5.2561},
$$




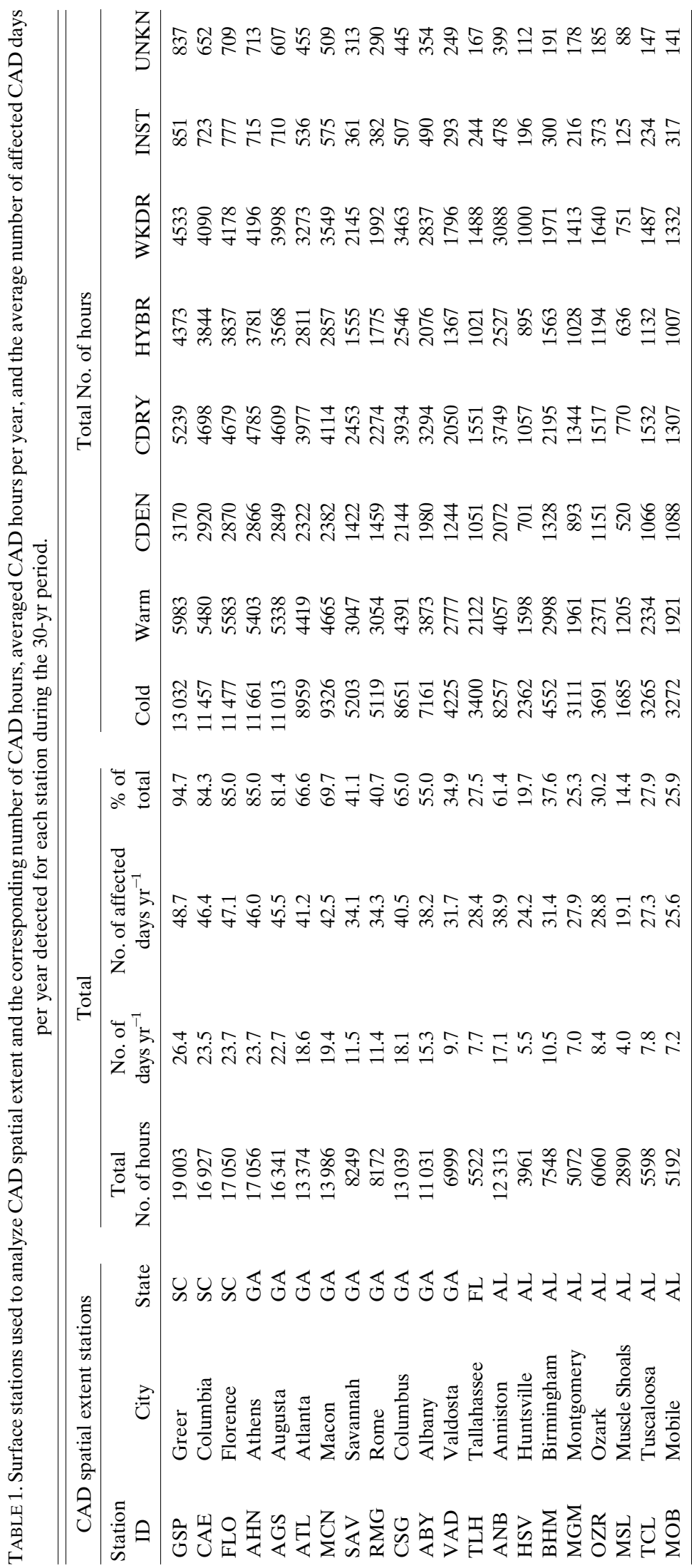


a.
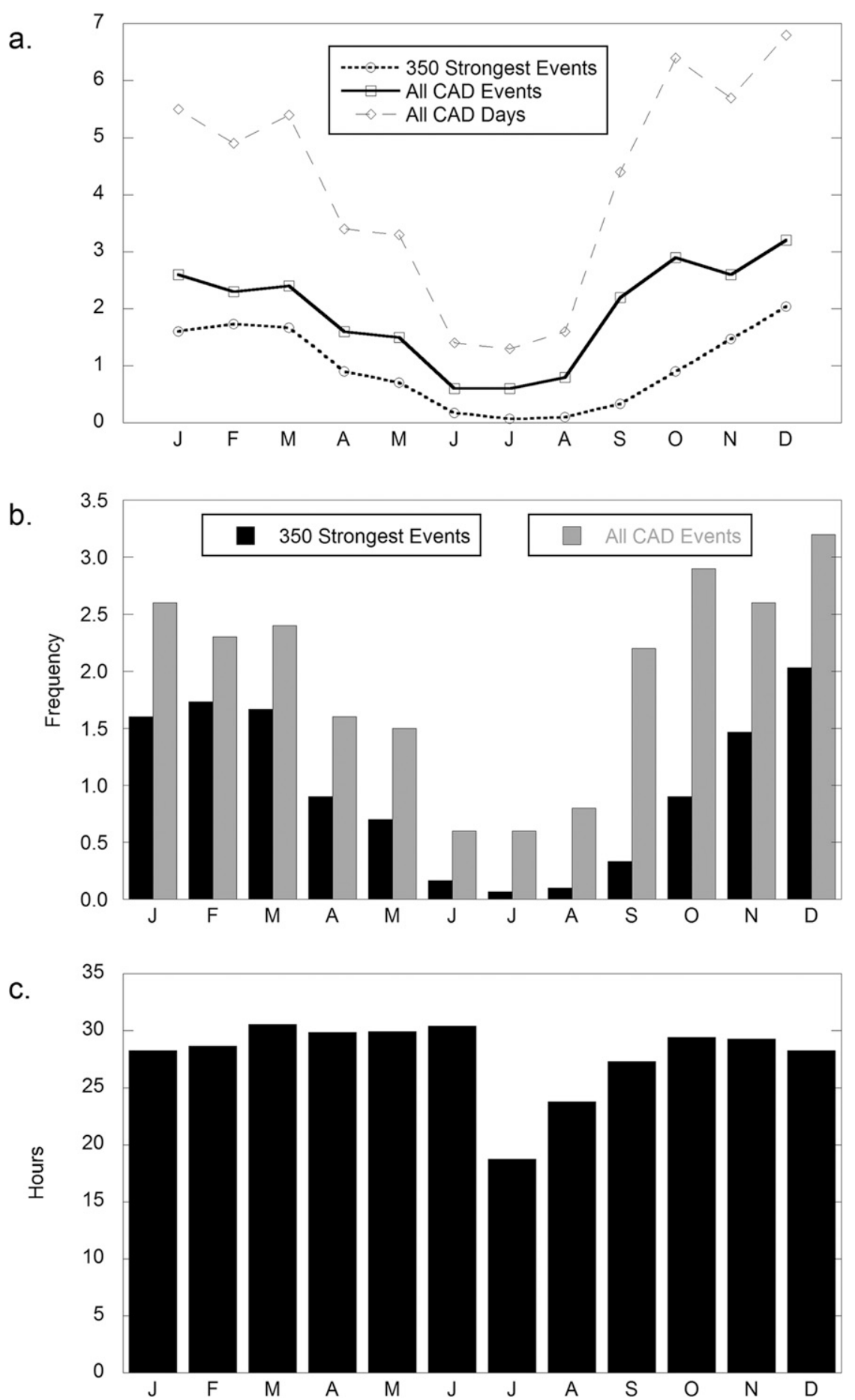

FIG. 3. (a) Monthly average frequency for all CAD days, all CAD events, and the strongest 350 CAD events. (b) Monthly frequency of CAD events and strongest 350 CAD events. (c) The average duration of events by month.

where $P_{\text {stn }}$ is the station pressure, $P_{a}$ is the altimeter reading, $R_{d}$ is the gas constant for dry air, and $h_{m}$ is the station height (Chu 1994). While this ensures the most complete dataset possible, it could account for inconsistencies between this study and previous studies utilizing different datasets. In addition, observations were linearly interpolated for cases with missing reports of six or fewer consecutive hours to reduce the effects of missing 
observations on CAD detection, temperature, sea level pressure, and station pressure.

The NCEI National Operational Model Archive and Distribution System (NOMADS) NARR-A online plotter was used to plot reanalyses of sea level pressure fields. NARR-A is available with 3-h temporal frequency and grid spacing of $32 \mathrm{~km} \times 32 \mathrm{~km}$. The central sea level pressure and location of parent highs were manually recorded using the NARR-A online plotter.

\section{Results}

\section{a. Extended objective climatology}

The CAD-detection algorithm was run using surface data for the 30-yr period from 1 January 1981 through 31 December 2010. Identified CAD frequency was analyzed by the number of hours, events, and affected days. All events included at least six CAD hours, while the CDEN and CDRY events included at least 25 CAD hours, as specified previously. CAD-affected days, hereafter referred to as CAD days, were those that included one or more CAD hours. Frequency was also stratified by CAD type and the month of occurrence to demonstrate seasonal variation.

The algorithm identified 703 events, affecting a total of 1504 days and encompassing $20069 \mathrm{~h}$ for the $30-\mathrm{yr}$ period. CAD events were detected somewhere in the region by the algorithm on $13.7 \%$ of days during the period, or more than 7 weeks $\mathrm{yr}^{-1}$ on average. While different events have varying impacts, this result demonstrates the significant amount of time each year that CAD affects the Southeast.

Average monthly frequencies for the strongest CAD events and the total CAD events and days are shown in Figs. $3 \mathrm{a}$ and $3 \mathrm{~b}$. The results support previous studies in showing a more active cold season (defined as 15 October-15 April) versus a less active warm season. December had the highest event frequency, with 3.2 CAD events occurring per year. October and January followed closely with 2.9 and 2.6 events each year, respectively. June, July, and August (JJA) had the lowest frequency of CAD events with 0.6, 0.6, and 0.8 events annually. For the $30-y r$ period, the summer months (JJA) had a total of 128 days of detected CAD. While summer months certainly see fewer CAD events, two summer events (17-22 August 1981 and 5-6 September 1996) ranked in the top $4 \%$ of all events by strength, indicating that while summer events are few and generally weak, strong summer events are possible.

There is a significant departure from B03's 12-yr climatology for the month of August. B03 described August as having a frequency of just over 3 events per year,

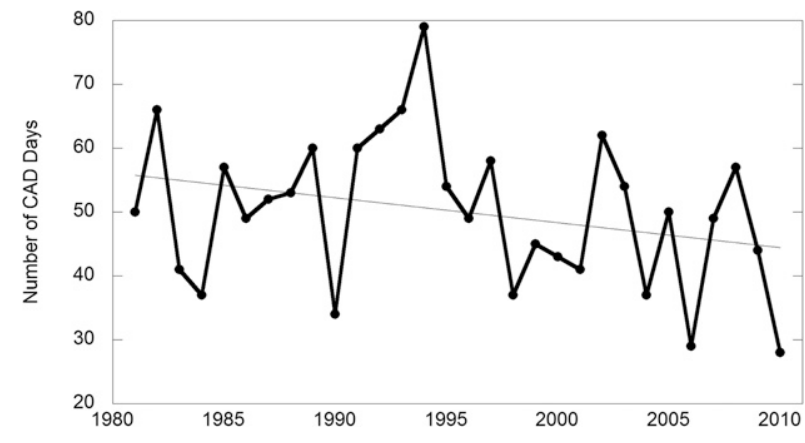

FIG. 4. Variations in the number of CAD days per year. The data have a statistically insignificant downward trend of 0.39 days $\mathrm{yr}^{-1}$.

while this study finds an average of 0.8 events per year over the $30-y r$ period. This difference is likely the result of the longer period and this study's decision to combine closely consecutive events dynamically forced by the same parent high.

Following previous studies (Bailey 2001; B03), CAD strength was computed for each event using a linear combination of normalized measurements for event duration, sea level pressure and potential temperature Laplacians, and magnitude of the along-barrier pressure gradient. B03 found that the frequency of the strongest cases more closely matched the Bell and Bosart (1988) 50-yr climatology. Indeed, the monthly frequency for the strongest 350 events in our study (shown in Fig. 3a) closely matches the results found by Bell and Bosart (1988), while the monthly frequency of all events shows a significant departure. Though the strongest 350 events showed a maximum during the winter months, the results demonstrate that strong events are still present during the spring and fall seasons when the wedge front can trigger convection.

Output from the CAD-detection algorithm was also analyzed by CAD hours per year, CAD events per year, and average CAD hours by month. Analysis of the average CAD hours by month was consistent with the event frequency by month. Very similar distributions for events per month, days per month, and hours per month indicate an approximately similar average length for individual CAD events across different months. Indeed, the average length of CAD events by month was clustered around $29 \mathrm{~h}$, with the exception of July and August. On average, July events had an average duration of only $19 \mathrm{~h}$, while August event durations averaged $24 \mathrm{~h}$. March events had the longest average duration at $31 \mathrm{~h}$. October had the highest average CAD hours at just over $87 \mathrm{CAD}$ hours each year, while the lowest month, July, saw only an average of 12 CAD hours $\mathrm{yr}^{-1}$. An analysis of CAD event frequency and hour 
TABLE 2. CAD event classifications by percentage of total occurrence, percentage of the strongest 350 events, and the average duration.

\begin{tabular}{|c|c|c|c|c|c|}
\hline Class & $\begin{array}{c}\% \text { of } \\
\text { total } \\
\text { events }\end{array}$ & $\begin{array}{c}\% \text { of the } \\
\text { strongest } \\
350 \\
\text { events }\end{array}$ & $\begin{array}{c}\text { Avg } \\
\text { No. of } \\
\text { events } \\
\text { per year }\end{array}$ & $\begin{array}{c}\text { Avg } \\
\text { duration } \\
\text { (h) }\end{array}$ & $\begin{array}{c}\text { Duration } \\
\text { range } \\
\text { (h) }\end{array}$ \\
\hline CDEN & 10.5 & 22.3 & 2.5 & 44.3 & $25-96$ \\
\hline CDRY & 17.2 & 34.3 & 4.0 & 45.2 & $25-126$ \\
\hline HYBR & 28.9 & 32.3 & 6.8 & 23.2 & $6-131$ \\
\hline WKDR & 30.7 & 18.7 & 7.2 & 22.0 & $6-134$ \\
\hline INST & 6.0 & 5.0 & 1.4 & 22.0 & $6-123$ \\
\hline UNKN & 6.7 & 4.0 & 1.6 & 19.9 & $6-71$ \\
\hline
\end{tabular}

frequency by year showed significant variability from year to year (Fig. 4). The most active year in the period was 1994, with 79 days and $1124 \mathrm{~h}$ recording CAD. The least active years were 2010 and 2006, with 28 CAD days (419 CAD hours) and 29 CAD days (365 CAD hours), respectively. The downward trend of 0.39 days $\mathrm{yr}^{-1}$, while intriguing and possibly related to slow $\left(0.0^{\circ}-\right.$ $0.11^{\circ} \mathrm{Cdecade}^{-1}$ ) upward trends in September-May temperatures across the United States during 1981-2010 (NCEI 2015; not shown), is not statistically significant at $p=0.05$.

Analysis was also stratified by CAD type (Table 2; Fig. 5). This revealed that weak/dry events were the most common, making up $31 \%$ of CAD events for the 30 -yr period and an average of $7.2 \mathrm{yr}^{-1}$. HYBR events followed closely with $29 \%$. CDRY, CDEN, UNKN, and INST events were $17 \%, 11 \%, 7 \%$, and $6 \%$, respectively. CDEN, CDRY, and WKDR events show a large peak in frequency during the cold season and minima during the summer months. HYBR monthly frequency is less clear, though the highest average HYBR events per month occurred in March. INST and UNKN events deviated from this pattern significantly. The INST monthly frequency shows a peak in April that continues through the summer months, while the UNKN monthly frequency appears to be bimodal with a secondary peak in June. It
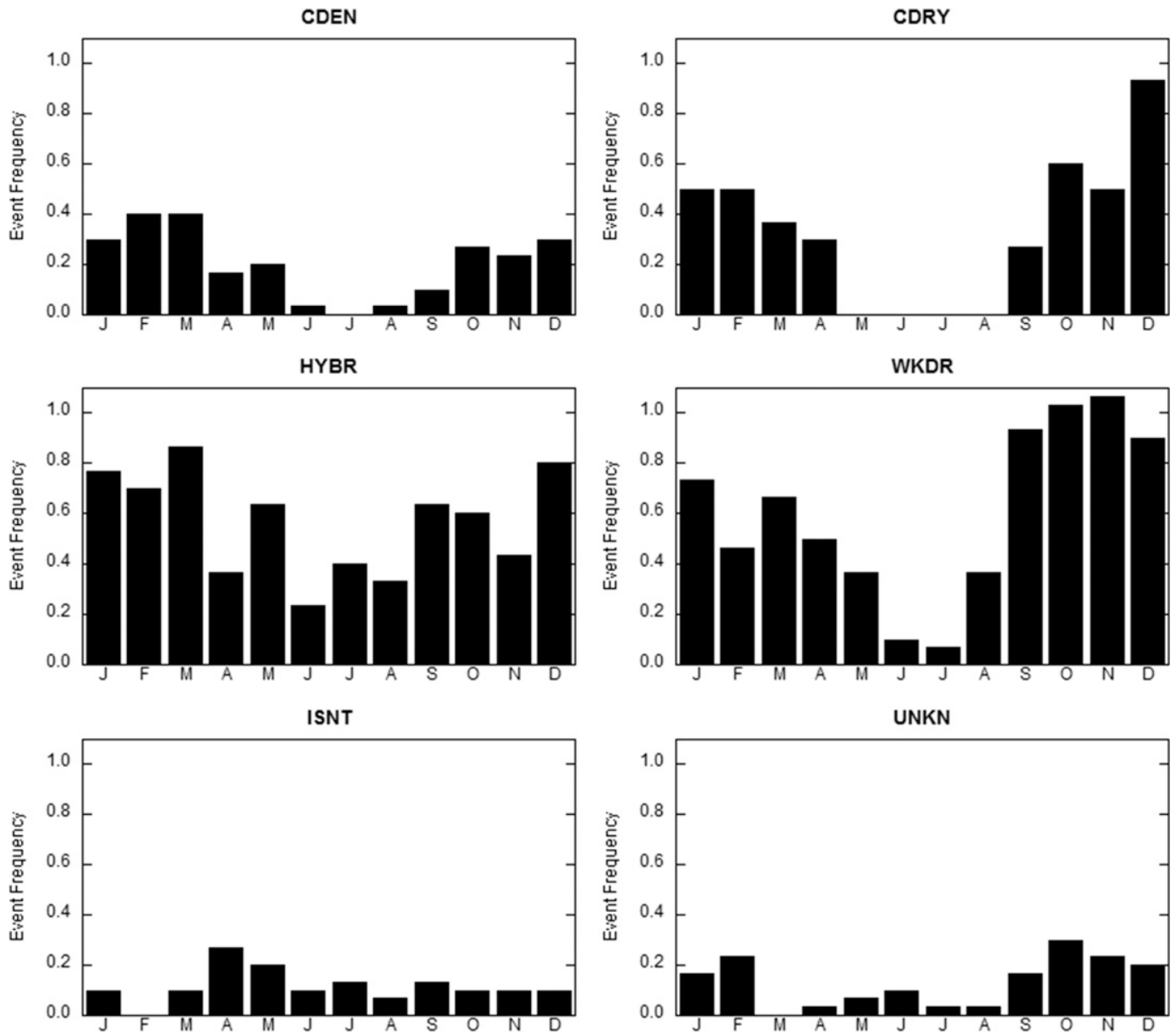

FIG. 5. The average frequency by month for the different CAD classifications. 


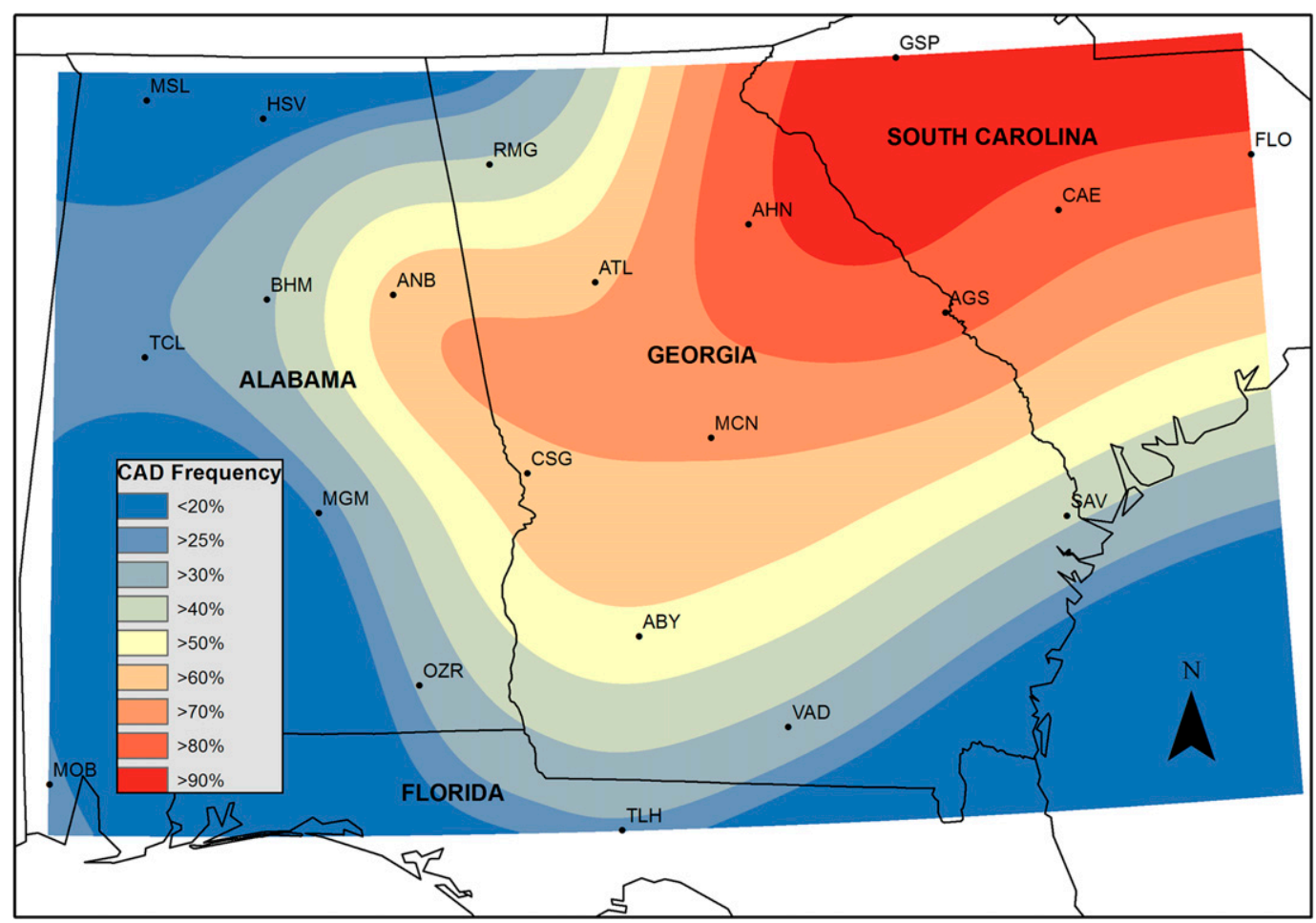

FIG. 6. Spatial extent and frequency within the southernmost extent of the damming region for all CAD events by percent of total CAD hours.

should be noted that these two categories were weaker in nature and therefore tend to have lower impact of sensible weather.

Classical-type events exhibited the longest per event average duration over the 30 -yr period (Table 2), in part because of classification constraints (i.e., classical types must be longer than $24 \mathrm{~h}$ in duration). CDEN events ranged from 25 to $96 \mathrm{~h}$ with an average length of $44.3 \mathrm{~h}$, and CDRY events ranged from 25 to $129 \mathrm{~h}$ with an average of $45.2 \mathrm{~h}$. HYBR, WKDR, and INST events average approximately half as long, with $23.2,22.0$, and $22.0 \mathrm{~h}$ per event, respectively, though their ranges (131, 134 , and $123 \mathrm{~h}$ respectively) include upper bounds similar to CDRY events. We speculate that the upper bound of the CDEN event range was possibly lower because of strong, but faster moving, parent highs. UNKN events recorded the shortest duration with an average of $19.9 \mathrm{~h}$ per event and a range of only $6-71 \mathrm{~h}$. While WKDR events represented the highest percentage of total events by class for the period, analysis of the strongest 350 events (i.e., the strongest $50 \%$ of events) shows HYBR and CDRY with the highest percentages, followed by CDEN (Table 2). We also speculate that the CDEN, CDRY, and HYBR events tend to be stronger than other CAD types, because their parent highs are stronger.

\section{b. Cold-dome spatial extent}

The spatial distribution of CAD events for the same $30-y r$ period demonstrates that large variability in the spatial extent of the cold-air dome exists from event to event. Detected CAD hours are broken down site by site and stratified by type and season in Table 1. Unsurprisingly, Greer, South Carolina, the northernmost site considered in this analysis, experienced the highest number of detected CAD hours. However, because Greer is not the northernmost point of the damming region, the $19003 \mathrm{CAD}$ hours detected specifically at Greer for the 30-yr period by the spatial extent algorithm fall short of the total number of CAD-algorithmdetected hours for the entire Southeast by $1066 \mathrm{~h}$. The most surprising result is the frequency with which the cold dome pushes into Alabama and parts of Florida (Fig. 6). On average, CAD was detected at Birmingham $252 \mathrm{~h}$ (10.5 days) $\mathrm{yr}^{-1}$ and $184 \mathrm{~h}$ (7.7 days) $\mathrm{yr}^{-1}$ at Tallahassee, Florida. Even Mobile, Alabama, detected $173 \mathrm{~h}$ (7.2 days) $\mathrm{yr}^{-1}$ on average.

To verify the results from this algorithm, a case for which the algorithm analyzed the dome over southern Alabama and northern Florida was selected. The Weather Prediction Center surface analysis for 0900 UTC 15 October 2009 [Fig. 7; see the supplementary material 


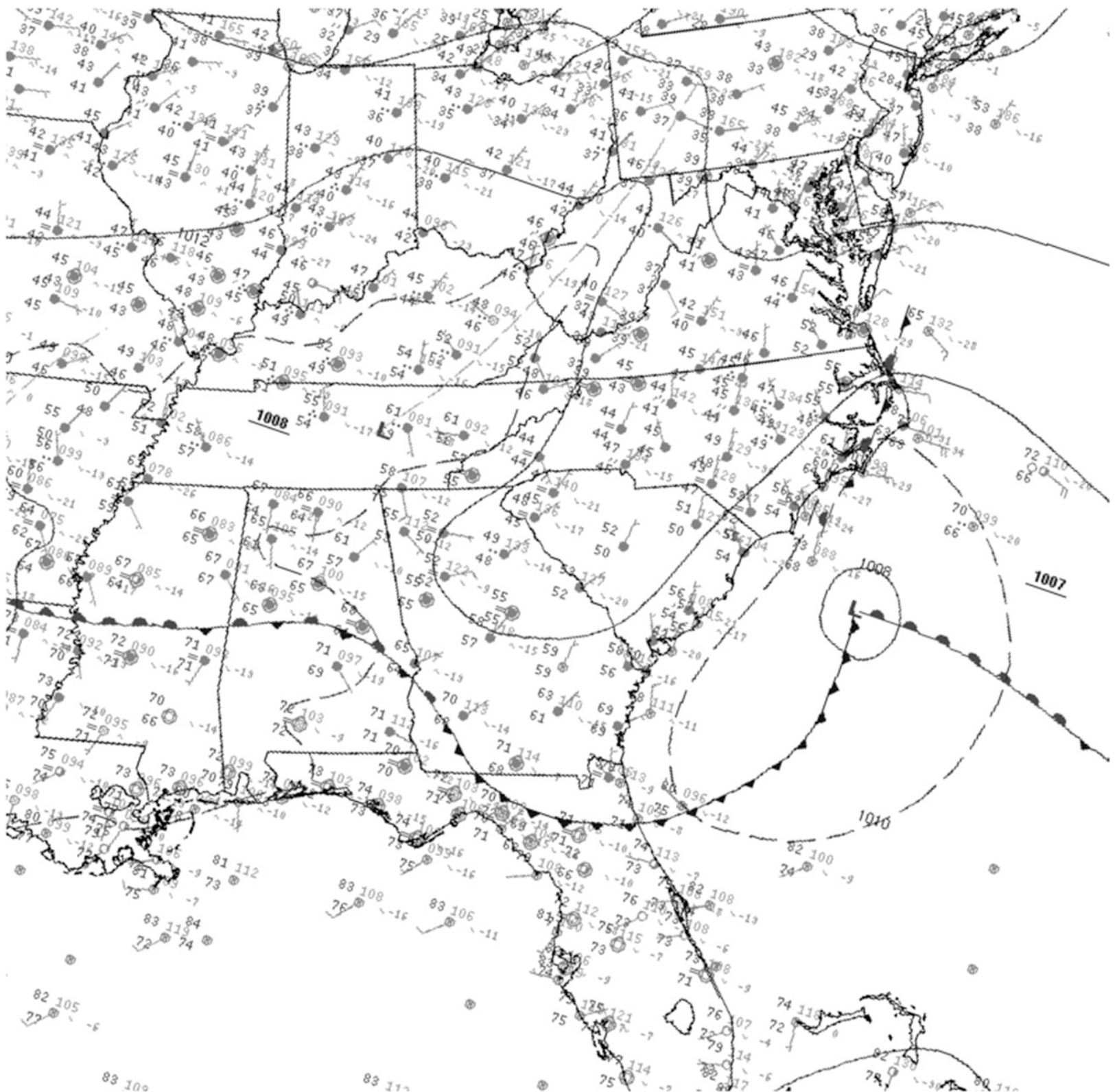

FIG. 7. WPC surface analysis for 0900 UTC 15 Oct 2009 showing a cold-air dome extending into southern AL and northern FL.

for an animation of the first author's simulation of this event using the Weather Research and Forecasting (WRF) Model] shows a case in which the cold-air dome, enhanced by a coastal low off the east coast of Florida, pushes well into this region. The algorithm performed well in correctly identifying and rejecting CAD presence at each station for the duration of the event. However, the algorithm did exhibit a tendency to sporadically falsely reject CAD for single hours when several stations within the cold dome reported calm winds. This may lead to a slight undercount in per station reported CAD hours, though the effect appears to be small. Thus, a new result of our climatology-that CAD is a real phenomenon all the way to the Gulf of Mexico-is robust.

Analysis of the overall spatial pattern for site-by-site CAD frequency shows two apparent lobes of the coldair dome: one extending to the west-northwest into Alabama and the second extending to the southwest toward Tallahassee (Fig. 6). Comparing these patterns to the regional elevation shows that the lobes tend to split around the region of higher terrain in east-central 

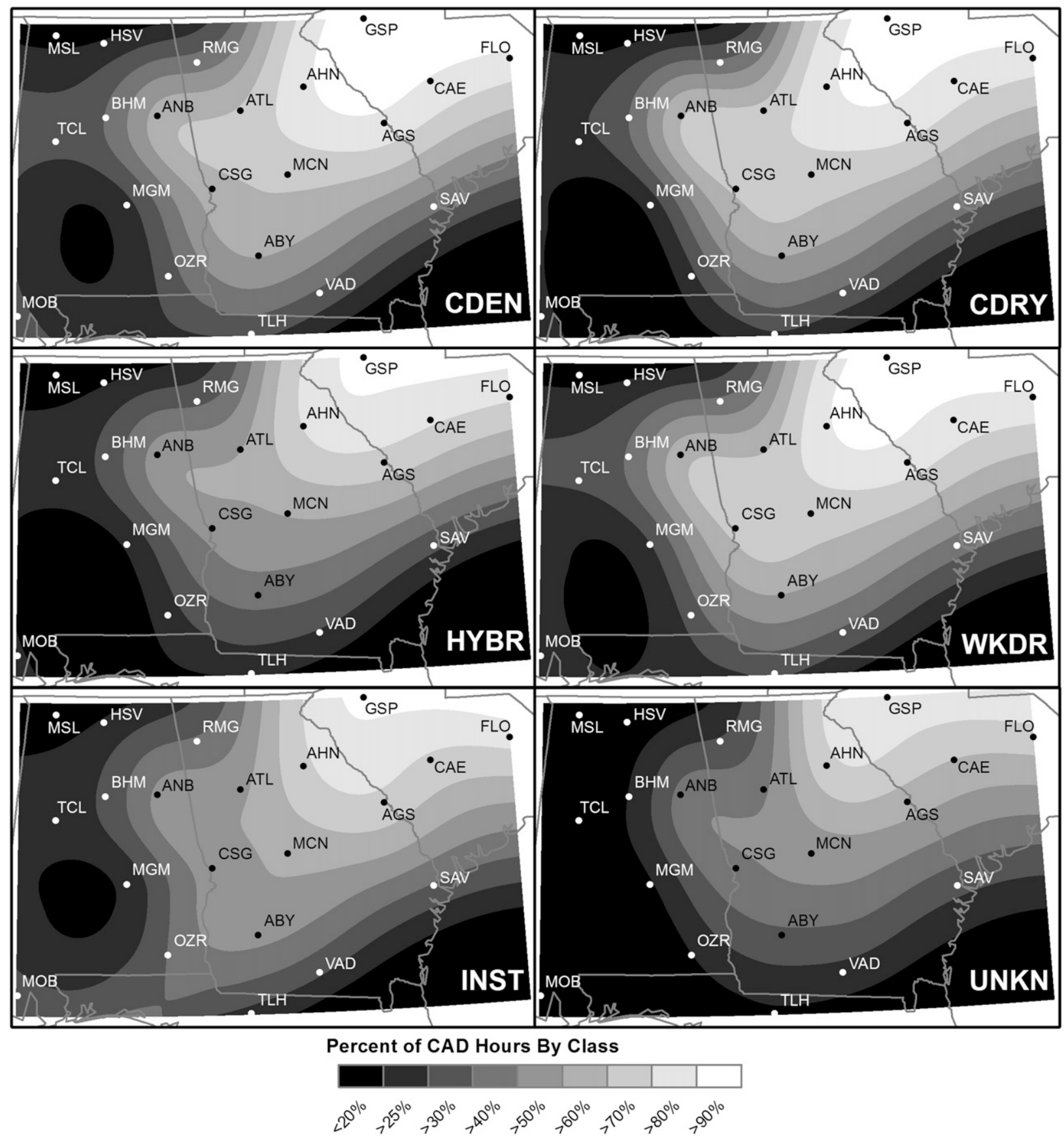

FIG. 8. CAD spatial extent and frequency by differing CAD classifications. Percentages are out of the total occurrence for each classification as determined by the CAD detection algorithm.

Alabama [e.g., Mount Cheaha, elevation $734 \mathrm{~m}(2407 \mathrm{ft})]$. Comparison of cold-season versus warm-season events (not shown) reveals that cold-season events slightly favored the west-northwesterly orientation into Alabama over the more southwesterly orientation into Florida. Warm-season events seem to favor both orientations equally, though the warm-season pattern over north-central Alabama indicates that a higher percentage of warm-season events push into that region than cold-season events.

A comparison of spatial extent and frequency by CAD type is shown in Figs. 8a-f. CDEN, CDRY, and HYBR events all tend to slightly favor the westnorthwesterly orientation into Alabama over the push 
into Florida. As these three classifications represent stronger synoptic forcing, the rightward turn to the westnorthwest is possibly due to the strengthened effect of the Coriolis force as stronger wind speeds develop in the area. At the same time, elevations decrease by more than a factor of 2 from the Smoky Mountains in Tennessee and North Carolina to the end of the Appalachians in Alabama, implying a doubling of the Froude number as the flow reaches Alabama and therefore a reduced blocking effect on these winds. Both INST and UNKN patterns show a displacement of the core of highest-frequency CAD to the northeast and seem to favor a southwesterly orientation. This is possibly due to the weak nature of these events as a result of little synoptic forcing.

\section{Conclusions}

This work objectively classifies cold-air damming along the southern Appalachians and maps its spatial extent within the southernmost damming region (i.e., South Carolina, Georgia, Alabama, and Florida) for a 30-yr period. While climatologies of cold-air damming have been constructed in the past, this study is the first to both objectively classify events and do so over a long period. In addition, mapping and analysis of the spatial extent of the cold dome across the southernmost damming region has not been performed previously. The purposes of this research are to assess the application of the B03 objective detection and classification schemes to longer time periods and to assess the frequency and extent to which the cold dome pushes into its southern reaches.

On average, CAD was detected by the algorithm on more than 50 days, or more than 7 weeks, each year. Fifty days per year is nontrivial for a phenomenon with the potential to significantly impact forecasts of sensible weather. As found in previous studies, detected CAD is much more frequent during the cold season than in the warm season. This can increase the potential for difficult winter weather forecasts with the threat of dangerous icy precipitation. However, the results also demonstrate that strong CAD events can occur during the spring and summer months when the cold-dome periphery may trigger or enhance convection.

Maps of cold-dome spatial extent reveal the surprisingly high frequency with which the cold dome pushes into portions of Florida and Alabama. Forecasters with CAD experience know that CAD can push as far west as Birmingham or as far south as Tallahassee; this study provides a quantitative measure of that assessment. The maps also indicate two potential trajectories once the dome pushes into central Georgia. A west-northwesterly path turns toward Anniston, Alabama, and north of the
Birmingham area. Its counterpart, the southwesterly trajectory, continues pushing into southwest Georgia and Florida. Cold-season events seemed to favor the westnorthwesterly orientation, as did the stronger CAD categories. With further research, these findings may provide forecasters with a quick estimate of where and how far the cold dome will push given the synoptic conditions. Future work utilizing the WRF Model (Rackley 2015; see supplementary material) will attempt to shed further light on why and how these two different trajectories form.

Acknowledgments. The authors thank The University of Georgia Graduate School for providing support for this work though funding from a graduate school assistantship. Special thanks are given to thesis committee members and reviewers for their helpful comments, and to Pam Knox for advice regarding climate trends for the eastern United States. Portions of this study were presented in poster form at the Annual Meeting of the American Meteorological Society, Phoenix, Arizona, on 4 January 2015.

\section{REFERENCES}

Bailey, C. M., G. Hartfield, G. M. Lackmann, K. Keeter, and S. Sharp, 2003: An objective climatology, classification scheme, and assessment of sensible weather impacts for Appalachian cold-air damming. Wea. Forecasting, 18, 641-661, doi:10.1175/1520-0434(2003)018<0641:AOCCSA > 2.0.CO;2.

Baker, A. K., 2009: Convection and Appalachian cold-air damming. M.S. thesis, Dept. of Marine, Earth and Atmospheric Sciences, North Carolina State University, $188 \mathrm{pp}$.

Baker, D. G., 1970: A study of high pressure ridges to the east of the Appalachian Mountains. Ph.D. thesis, Massachusetts Institute of Technology, $127 \mathrm{pp}$.

Ballentine, R. J., 1980: A numerical investigation of New England coastal frontogenesis. Mon. Wea. Rev., 108, 1479-1497, doi:10.1175/1520-0493(1980)108<1479:ANIONE > 2.0.CO;2.

Bell, G. D., and L. F. Bosart, 1988: Appalachian cold-air damming. Mon. Wea. Rev., 116, 137-161, doi:10.1175/ 1520-0493(1988)116<0137:ACAD>2.0.CO;2.

Bosart, L. F., C. J. Vaudo, and J. H. Helsdon Jr., 1972: Coastal frontogenesis. J. Appl. Meteor., 11, 1236-1258, doi:10.1175/ 1520-0450(1972)011<1236:CF >2.0.CO;2.

Burden, R. L., and J. D. Faires, 1993: Numerical Analysis. 5th ed. PWS Publishing Co., 768 pp.

Chu, R., 1994: Algorithms for the Automated Surface Observing System (ASOS). ISL Office Note 94-4, NWS/OSD, 106 pp.

Forbes, G. S., R. A. Anthes, and D. W. Thomson, 1987: Synoptic and mesoscale aspects of an Appalachian ice storm associated with cold-air damming. Mon. Wea. Rev., 115, 564-591, doi:10.1175/1520-0493(1987)115<0564:SAMAOA > 2.0.CO;2.

Fritsch, J. M., J. Kapolka, and P. A. Hirschberg, 1992: The effects of subcloud-layer diabatic processes on cold air damming. J. Atmos. Sci., 49, 49-70, doi:10.1175/1520-0469(1992)049<0049: TEOSLD $>2.0 . \mathrm{CO} ; 2$.

Garreaud, R. D., and J. M. Wallace, 1998: Summertime incursions of midlatitude air into subtropical and tropical South America. Mon. Wea. Rev., 126, 2713-2733, doi:10.1175/ 1520-0493(1998)126<2713:SIOMAI >2.0.CO;2. 
Green, T. A., Jr., 2006: Cold air damming erosion and associated precipitation in the southeastern United States. M.S. thesis, Dept. of Marine, Earth and Atmospheric Sciences, North Carolina State University, 248 pp.

Grumm, R. H., 2015: Mid-Atlantic ice storm 4 March 2015. National Weather Service, State College, PA, accessed 22 July 2015, 30 pp. [Available online at http://cms.met.psu.edu/sref/ severe/2015/03Mar2015.pdf.]

Hartfield, G., 1998: Cold air damming: An introduction. National Weather Service Eastern Region Training and Evaluation Module 4,16 pp. [Available online at http://www.erh.noaa.gov/ $\mathrm{er} / \mathrm{hq} / \mathrm{ssd} / \mathrm{erps} / \mathrm{tem} / \mathrm{tem} 4 . \mathrm{pdf}$.

, K. Keeter, and P. Badgett, 1996: Spectrum of cold air damming and damming look-alikes. [Available from the National Weather Service Office, 1005 Capability Dr. 300, Raleigh, NC 27606.]

Keeter, K. K., S. Businger, L. G. Lee, and J. S. Waldstreicher, 1995: Winter weather forecasting throughout the eastern United States. Part III: The effects of topography and the variability of winter weather in the Carolinas and Virginia. Wea. Forecasting, 10, 4260, doi:10.1175/1520-0434(1995)010<0042:WWFTTE $>2.0 . C O ; 2$.

Kramer, D., 1997: Real-time mesoscale model evaluation during Appalachian cold air damming. M.S. thesis, Dept. of Marine, Earth, and Atmospheric Sciences, North Carolina State University, $139 \mathrm{pp}$.

Lackmann, G. M., 2011: Midlatitude Synoptic Meteorology: Dynamics, Analysis, and Forecasting. Amer. Meteor. Soc., 345 pp.

— mechanisms, synoptic settings, and model representation. Preprints, 20th Conf. on Weather Analysis and Forecasting/16th Conf. on Numerical Weather Prediction, Seattle, WA, Amer. Meteor. Soc., 18.6. [Available online at https://ams.confex.com/ ams/pdfpapers/73411.pdf.]

Langmaid, A. H., and A. J. Riordan, 1998: Surface mesoscale processes during the 1994 Palm Sunday tornado outbreak. Mon. Wea. Rev., 126, 2117-2132, doi:10.1175/1520-0493(1998)126<2117: SMPDTP $>2.0 . \mathrm{CO} ; 2$.
Lee, L. G., K. K. Keeter, S. Businger, and A. J. Riordan, 1992: Geography-related forecasting problems in the southeastern United States and a joint North Carolina State UniversityNational Weather Service effort to improve the understanding and prediction of these events. Preprints, Symp. on Weather Analysis and Forecasting, Atlanta, GA, Amer. Meteor. Soc., 166-172.

Mesinger, F., and Coauthors, 2006: North American Regional Reanalysis. Bull. Amer. Meteor. Soc., 87, 343-360, doi:10.1175/ BAMS-87-3-343.

NCEI, 2015: Climate at a glance. NOAA, accessed 23 July 2015. [Available online at http://www.ncdc.noaa.gov/cag/.]

Rackley, J. A., 2015: Southern Appalachian cold air damming: A climatology and simulation of case studies. M.S. thesis, Dept. of Geography, The University of Georgia, $113 \mathrm{pp}$.

Richwien, B. A., 1980: The damming effect of the southern Appalachians. Natl. Wea. Dig., 5 (1), 2-12.

Smith, R. B., 1982: Synoptic observations and the theory of orographically disturbed wind and pressure. J. Atmos. Sci., 39, 60-70, doi:10.1175/1520-0469(1982)039<0060:SOATOO >2.0.CO;2.

Stanton, W., 2003: An analysis of the physical processes and model representation of cold air damming erosion. M.S. thesis, Dept. of Marine, Earth and Atmospheric Sciences, North Carolina State University, $207 \mathrm{pp}$.

Stauffer, D. R., and T. T. Warner, 1987: A numerical study of Appalachian cold-air damming and coastal frontogenesis. Mon. Wea. Rev., 115, 799-821, doi:10.1175/1520-0493(1987)115<0799: ANSOAC $>2.0 . C O ; 2$.

Xu, Q., 1990: A theoretical study of cold air damming. J. Atmos. Sci., 47, 2969-2985, doi:10.1175/1520-0469(1990)047<2969: ATSOCA $>2.0 . \mathrm{CO} ; 2$.

_ , and S. Gao, 1995: An analytic model of cold air damming and its applications. J. Atmos. Sci., 52, 353-366, doi:10.1175/ 1520-0469(1995)052<0353:AAMOCA > 2.0.CO;2.

,,- , and B. H. Fiedler, 1996: A theoretical study of cold air damming with upstream cold air inflow. J. Atmos. Sci., 53, 312326, doi:10.1175/1520-0469(1996)053<0312:ATSOCA >2.0.CO;2. 